\title{
Interleukin-1 $\alpha$ induces immunosuppression by mesenchymal stem cells promoting the growth of prostate cancer cells
}

\author{
JIWEN CHENG ${ }^{1 *},{\text { LING } \text { LI }^{2 *}, \text { YAN LIU }^{2 *}, \text { ZHIROU WANG }}^{1}$, XIAODONG ZHU ${ }^{2}$ and XIANZHONG BAI ${ }^{1}$ \\ Departments of ${ }^{1}$ Urology and ${ }^{2}$ Radiation Therapy, Affiliated Tumor Hospital of Guangxi Medical University, \\ Nanning, Guangxi 530021, P.R. China
}

Received February 11, 2012; Accepted June 15, 2012

DOI: $10.3892 / \mathrm{mmr} .2012 .1019$

\begin{abstract}
Mesenchymal stem cells (MSCs) are generally used in tissue engineering, regenerative medicine and therapy for immune disorder disease. MSCs are also employed as drug carriers for tumor therapy due to their ability to migrate to tumor tissue. However, due to the immunosuppressive function of MSCs, the application of MSCs in prostate cancer therapy remains limited. In this study, we investigated the underlying mechanism by which MSCs enable prostate cancer cells to escape from immune surveillance in the inflammatory microenvironment. Firstly, we demonstrated that compared with the control groups, MSCs pretreated with IL-1 $\alpha$ effectively promoted the growth of the mouse prostate cancer cell line RM-1 in vivo. Furthermore, when RM-1 prostate cancer cells were co-injected with MSCs pretreated with IL-1 $\alpha$, tumor incidence significantly increased in allogeneic recipients. In addition, we investigated the mechanism through which MSCs promote the ability of RM-1 cells to escape from immune injury. The results revealed that IL-1 $\alpha$ led to the upregulation of TGF- $\beta$ in MSCs. The inflammatory cytokine-induced promotive effect of MSCs on RM-1 cells in vivo was inhibited by TGF- $\beta$ siRNA. The results of our study suggest that inflammatory cytokines induce the immunosuppressive function of MSCs which enables prostate cancer cells to escape from immune injury.
\end{abstract}

\section{Introduction}

Mesenchymal stem cells (MSCs), which originate from the mesodermal germ layer, are a subset of non-hematopoietic stem cells that exist in the bone marrow $(1,2)$. MSCs have been described as an adherent, fibroblast-like population

Correspondence to: Dr Xianzhong Bai, Department of Urology, Affiliated Tumor Hospital, Guangxi Medical University, No. 71, Hedi Road, Nanning, Guangxi 530021, P.R. China

E-mail: 872544361@qq.com

${ }^{*}$ Contributed equally

Key words: mesenchymal stem cells, prostate cancer cell, interleukin- $1 \alpha$, transforming-growth factor- $\beta$ and have the ability to differentiate into multiple lineages, including chondrocytes, osteocytes, adipocytes, myocytes and astrocytes, and are a potential source of stem cells for cellular and genetic therapy $(3,4)$. MSCs also exist in other tissues, including adipose tissue, umbilical cord, fetal liver, muscle and lung (3,5-8). MSCs are capable of expanding more than $10^{4}$-fold in culture without loss of their multilineage differentiation potential.

The immunosuppressive function of MSCs has been reported in several studies (9-12). Koç et al reported that when allogeneic MSCs were infused along with allogeneic bone marrow into patients with metachromatic leukodystrophy or Hurler's syndrome, there was no evidence of alloreactive T cells and no incidence of GvHD (13). MSCs have also been used to prevent or treat autoimmune diseases, including experimental autoimmune encephalomyelitis and collagen-induced arthritis $(14,15)$.

MSCs have a tropism for tumors (16) and several studies have reported contradictory results concerning the effect of MSCs on tumor growth. Hall et al (17) demonstrated that the co-culturing of ALL cell lines with VCAM-1-overexpressing stromal cells enhanced the survival of the leukemic cells in a PI-3 kinase-dependent manner, compared with co-culturing with stromal cells expressing only endogenous VCAM-1. Djouad et al (18) revealed that MSCs exhibit side effects related to systemic immunosuppression that favor induced tumor growth in vivo. Conversely, MSCs have been reported to be anti-tumorigenic in a mouse model of Kaposi's sarcoma by inhibiting AKT activity (19). Tumorigenesis is always associated with chronic inflammation. Therefore, it is essential to observe the effects of MSCs on tumor growth in an inflammatory environment.

In this study, we used the RM-1 prostate cancer cell line to investigate the effect of MSCs on tumor growth in an inflammatory environment. The incidence and development of prostate cancer is often accompanied by an inflammatory microenvironment. Therefore, it is important to determine the mechanism of the inflammatory cytokine-induced immunosuppressive effect of MSCs in prostate cancer cells.

\section{Materials and methods}

Reagents. Recombinant mouse IL-1 $\alpha$ was from Peprotech, Inc. (La Jolla, CA, USA). Anti-mouse CD34, CD45, CD90, 
CD105 and CD29 antibodies were from eBioscience (San Diego, CA, USA).

Cells and animals. MSCs were generated from bone marrow flushed out of the tibias and femurs of 4-6-week-old mice. The cells were cultured in DMEM medium supplemented with $10 \%$ fetal bovine serum (FBS), $2 \mathrm{mM}$ glutamine, $100 \mathrm{U} / \mathrm{ml}$ penicillin and $100 \mathrm{mg} / \mathrm{ml}$ streptomycin (Invitrogen, Carlsbad, CA, USA). Non-adherent cells were removed after $72 \mathrm{~h}$ and adherent cells were maintained with medium replenishment every 3 days.

The murine prostate cancer cell line RM-1 was cultured at $37^{\circ} \mathrm{C}$ with $5 \%$ of $\mathrm{CO}_{2}$ in RPMI-1640 with $10 \%$ FBS, supplemented with $2 \mathrm{mM}$ L-glutamine, $100 \mathrm{U} / \mathrm{ml}$ penicillin and $100 \mu \mathrm{g} / \mathrm{ml}$ streptomycin. Cells were subcultured every 3 days when they reached $70-80 \%$ confluence.

Male Balb/c and C57BL/6 mice, 6-8 weeks old, were purchased from the Shanghai Experimental Animal Center of the Chinese Academy of Sciences, Shanghai, China. Mice were housed in pathogen-free conditions and all procedures were performed according to the guidelines of the Committee on Animals of the Chinese Academy of Sciences.

Multi-differentiation of MSCs. MSCs were cultured with an osteoinductive medium consisting of DMEM supplemented with $10 \%$ FBS, $\beta$-mercaptoethanol, $100 \mu \mathrm{M}$ L-ascorbic acid, $10 \mathrm{nM}$ dexamethasone and $10 \mathrm{mM} \beta$-glycerophosphate for 14 days. The cells were then stained with alizarin red to reveal calcium deposition, characteristic of osteoblasts. MSCs were induced to differentiate into adipocytes by culturing with DMEM supplemented with $0.5 \mathrm{mM}$ isobutylmethylxanthine, $60 \mu \mathrm{M}$ indomethacin, $10 \mathrm{nM}$ dexamethasone and $10 \mu \mathrm{g} / \mathrm{ml}$ insulin for 14 days. The formation of adipocytes was verified by staining for triglycerides with Oil red $\mathrm{O}$ to detect intracellular lipid accumulation.

RM-1 murine prostate cancer model. RM-1 cells and MSCs were prepared either as single-cell type suspensions $\left(1 \times 10^{6}\right.$ cells in $200 \mu \mathrm{l}$ PBS $)$ or as a mixture of cells $\left(1 \times 10^{6} \mathrm{RM}-1\right.$ cells and $2 \times 10^{5}$ MSCs in $200 \mu \mathrm{l}$ of PBS). RM-1 cells (alone or mixed with MSCs) were subcutaneously administered in the armpit area of Balb/c or C57BL/6 mice. The mice were examined every day and tumor growth was evaluated by measuring the length and width of the tumor mass. At the end of the experiment, the animals were sacrificed and the tumors were removed. The tumor masses were weighed and analyzed histologically.

Conditioned medium. MSCs were stimulated by culturing with IL-1 $\alpha(20 \mathrm{ng} / \mathrm{ml})$ for $12 \mathrm{~h}$. The culture medium was then abandoned and replaced with DMEM culture medium without FBS. After culturing for a further $24 \mathrm{~h}$, the conditioned medium was collected, as well as a $0.22-\mu \mathrm{m}$ filtrate of the supernatant medium from the MSCs.

Allogeneic implantation of RM-1 cells. RM-1 cells and MSCs were prepared either as single-cell type suspensions $\left(1 \times 10^{6}\right.$ cells in $200 \mu \mathrm{l}$ of PBS) or as a mixture of cells $\left(1 \times 10^{6} \mathrm{RM}-1\right.$ cells and $2 \times 10^{5}$ MSCs in $200 \mu \mathrm{l}$ PBS). Subcutaneous administration of RM-1 cells (alone or mixed with MSCs) was performed in the armpit area of C57/BL6 mice. Tumor incidence was evaluated 3 times per week.
Mixed lymphocyte reaction (MLR). Mouse spleens were disaggregated into $10 \mathrm{ml}$ RPMI-1640 medium to isolate splenocytes. Erythrocytes were lysed with $0.84 \% \mathrm{NH}_{4} \mathrm{Cl}$ and subsequently washed 3 times with RPMI-1640. Trypan blue dye exclusion was used to assess cell count and viability. Splenocytes were incubated with $5 \mu \mathrm{g} / \mathrm{ml}$ concanavalin A (ConA; Sigma-Aldrich, St. Louis, MO, USA) for $72 \mathrm{~h}$ and then cultured with IL-2 (200 U/ml) for proliferation. Splenocyte cultures were maintained in RPMI-1640 medium supplemented with 10\% FBS, $2 \mathrm{mM}$ glutamine, $100 \mathrm{U} / \mathrm{ml}$ penicillin, $100 \mathrm{mg} / \mathrm{ml}$ streptomycin and $50 \mathrm{mM}$ of $\beta$-ME (complete medium). MSCs were added to the MLR to provide a $200-\mu 1$ final volume. Following 3 days of incubation, $1 \mu \mathrm{Ci} /$ well $(0.037 \mathrm{MBq} /$ well $){ }^{3} \mathrm{H}$-thymidine was added overnight and thymidine incorporation was measured using a $\beta$-scintillation counter. The data were presented as the percentage of the relative proliferative response, corresponding to the mean counts per min (cpm) of a responder stimulator pair in the absence of MSCs which was attributed a $100 \%$ value.

Real-time PCR. MSCs were incubated with IL-1 $\alpha(20 \mathrm{ng} / \mathrm{ml})$ for $12 \mathrm{~h}$ and the total cell mRNA was collected with TRIzol reagent (Invitrogen). cDNA was synthesized using M-MLV reverse transcriptase (Promega Corporation, Madison, WI, USA) and $2 \mu \mathrm{g}$ total RNA and oligo dT18-primers. PCR amplification was carried out using 2- $\mu 1$ aliquots of cDNA. Real-time PCR was performed in triplicate using the SYBR PrimeScript RT-PCR kit (Takara Bio, Inc., Shiga, Japan). The primer sequences for TGF- $\beta$ were: forward, 5'-TGTCACCGGAGTTGTGCGGC-3'; reverse, 5'-CTCGGCGGCCGGTAGTGAAC-3'. Total sample RNA was normalized to endogenous $\beta$-actin mRNA. Thermocycler conditions included an initial hold at $50^{\circ} \mathrm{C}$ for 2 min and then $95^{\circ} \mathrm{C}$ for $10 \mathrm{~min}$, followed by a two-step PCR program of $95^{\circ} \mathrm{C}$ for $15 \mathrm{sec}$ and $60^{\circ} \mathrm{C}$ for $60 \mathrm{sec}$ repeated for 40 cycles using an Mx 4000 system (Stratagene, La Jolla, CA, USA) on which data were collected and quantitatively analyzed. Expression levels of mRNA were presented as fold changes relative to an untreated control.

Western blot analysis. Cells were washed with PBS solution, and protein was then extracted according to an established protocol. Furthermore, proteins were mixed with Laemmli sample buffer, heated at $65^{\circ} \mathrm{C}$ for $10 \mathrm{~min}$, loaded $(20 \mu \mathrm{g}$ for each sample), separated by sodium dodecyl sulfate-polyacrylamide gel $(7.5 \%)$ electrophoresis under denaturing conditions and electroblotted onto nitrocellulose membranes. The nitrocellulose membranes were blocked by incubation in blocking buffer (1\% BSA in Tris-buffered saline-0.1\% Tween 20), incubated with anti-TGF- $\beta$-antibody (Abcam, Cambridge, UK), and washed and incubated with anti-rabbit peroxidase-conjugated secondary antibody (Invitrogen). Signals were visualized by chemiluminescent detection. Blots were quantified using Quantity One software from Bio-Rad (Hercules, CA, USA), and TGF- $\beta$ expression was normalized to values in the control group. Equal loading of samples was verified by Coomassie blue staining of simultaneously run gels. Gels were run 4 times and the images shown are representative.

Statistical analysis. Statistical analysis of the data was performed using GraphPad Prism 4 software. The Student's 
A

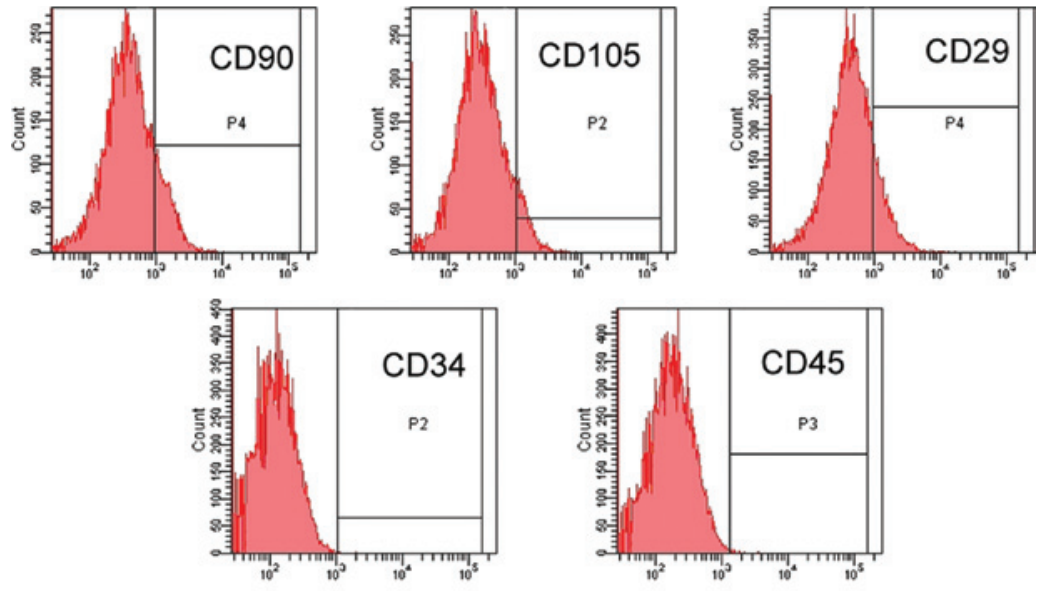

B

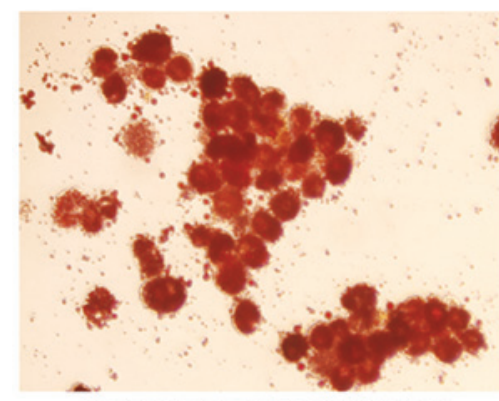

Adipogenic differentiation

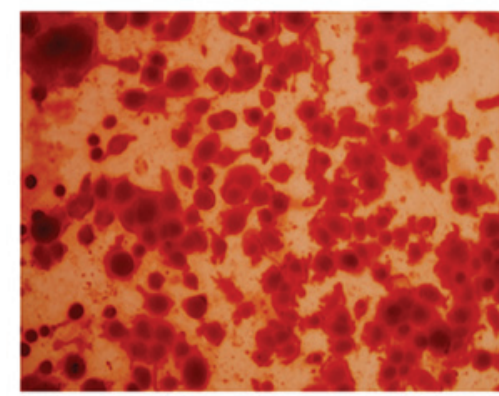

Osteogenic differentiation

Figure 1. Identification of MSCs. (A) MSCs were stained with commercially available antibodies for analysis of surface markers by flow cytometry. (B) MSCs were cultured under different conditions to differentiate into either adipocytes or osteoblasts. The presence of triglycerides, characteristic of adipocytes, was revealed by staining with Oil Red O. Alizarin red staining was used to reveal calcium deposition, indicative of osteoblasts. MSCs, mesenchymal stem cells.

t-test was used to compare the mean values of the two groups. Data among 3 or more groups were compared using the one-way analysis of variance, followed by the Dunnett's post hoc test. Final values were expressed as the mean \pm SEM. $\mathrm{P}<0.05$ was considered to indicate a statistically significant result.

\section{Results}

Pretreatment of MSCs with inflammatory cytokines promotes the growth of RM-1 prostate cancer cells in vivo. We identified long spindle-shaped fibroblastic cells isolated from bone marrow by examining their surface markers and ability to differentiate. The results demonstrated that these cells were positive for CD90, CD105 and CD29 and negative for CD34 and CD45. Furthermore, these cells differentiated into adipocytes and osteoblast-like cells. The results indicated that the cells isolated from the bone marrow had properties that were consistent with those of MSCs (Fig. 1A and B).

MSCs, which were either pretreated with inflammatory cytokines IL-1 $\alpha$ or not, were co-injected with RM-1 cells into Balb/c mice. We found that a more rapid growth of the RM-1 cells that were mixed with non-pretreated MSCs in vivo than that of the RM-1 cells alone. Compared with the control group, MSCs pretreated with IL-1 $\alpha$ demonstrated a tumorpromoting effect (Fig. 2). Conditioned media were collected from the MSCs and IL-1 $\alpha$-pretreated MSCs. The conditioned media were infused into subcutaneous RM-1 tumor-bearing

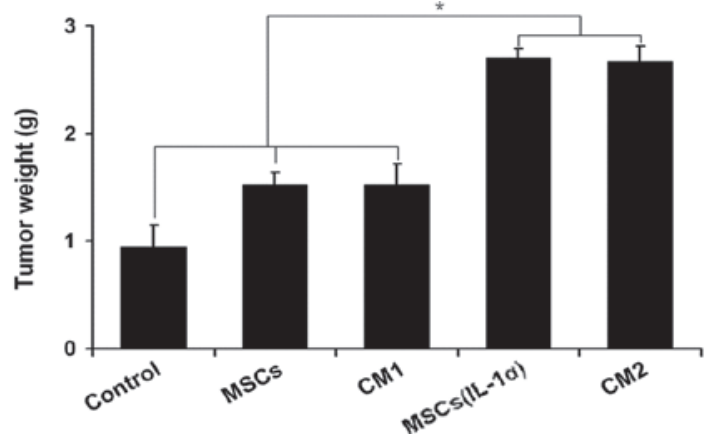

Figure 2. Inflammatory cytokine-pretreated MSCs promoted the growth of RM-1 prostate cancer cells in vivo. Balb/c mouse MSCs $\left(2 \times 10^{5}\right)$ were pretreated with IL-1 $\alpha(20 \mathrm{ng} / \mathrm{ml})$ for $12 \mathrm{~h}$, mixed with RM-1 cells $\left(1 \times 10^{6}\right)$ and subcutaneously administered in the armpit area of Balb/c mice. The mice were sacrificed 14 days following implantation, the tumors were dissected and their weights were measured. In addition, the conditioned media CM1, from MSCs, and CM2, from IL-1 $\alpha$-pretreated MSCs, were collected. The conditioned media were infused via the tail vein once every 3 days into Balb/c mice that had been implanted with RM-1 cells. The weights of the tumors were measured following removal of the tumors from the mice $\left({ }^{*} \mathrm{P}<0.05\right)$. MSCs, mesenchymal stem cells; CM1, conditioned medium 1; CM2, conditioned medium 2.

mice via tail vein injection. Compared with the control groups, the conditioned medium from IL-1 $\alpha$-pretreated MSCs significantly enhanced the tumor growth in vivo (Fig. 2). These results indicate that IL- $1 \alpha$ stimulates MSCs to promote the growth of RM-1 tumors in vivo. 


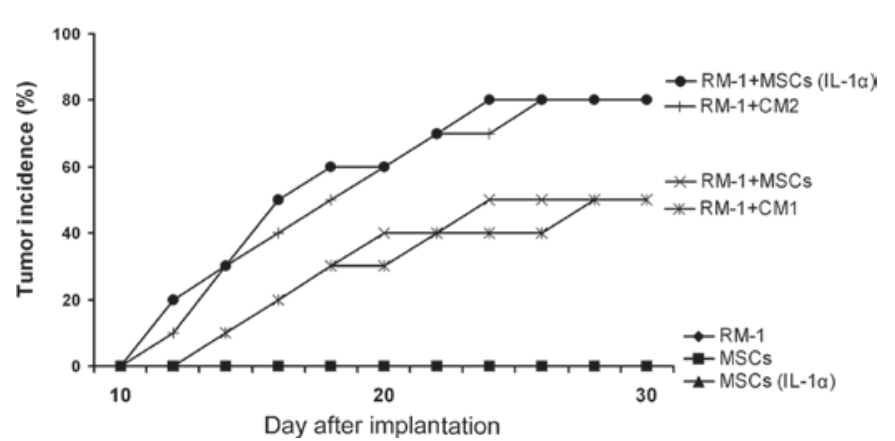

Figure 3. RM-1 prostate cancer cells are not rejected by C57BL/6 mice when co-injected with MSCs. C57/BL6 mouse MSCs $\left(2 \times 10^{5}\right)$ were pretreated with IL-1 $\alpha(20 \mathrm{ng} / \mathrm{ml})$ for $12 \mathrm{~h}$, mixed with RM-1 cells $\left(1 \times 10^{6}\right)$ and then subcutaneously administered in the armpit area of C57BL/6 mice. In addition, the conditioned media CM1, from MSCs, and CM2, from IL-1 $\alpha$-pretreated MSCs, were collected. The conditioned media were infused via the tail vein once every 3 days into Balb/c mice that had been implanted with RM-1 cells. Tumor incidence was observed to evaluate the immunosuppressive function of the MSCs that assisted the RM-1 cells to escape from immunological rejection by the Balb/c mice. As negative controls, RM-1 cells or MSCs alone were implanted in the C57/BL6 mice. MSCs, mesenchymal stem cells; CM1, conditioned medium $1 ; \mathrm{CM} 2$, conditioned medium 2.

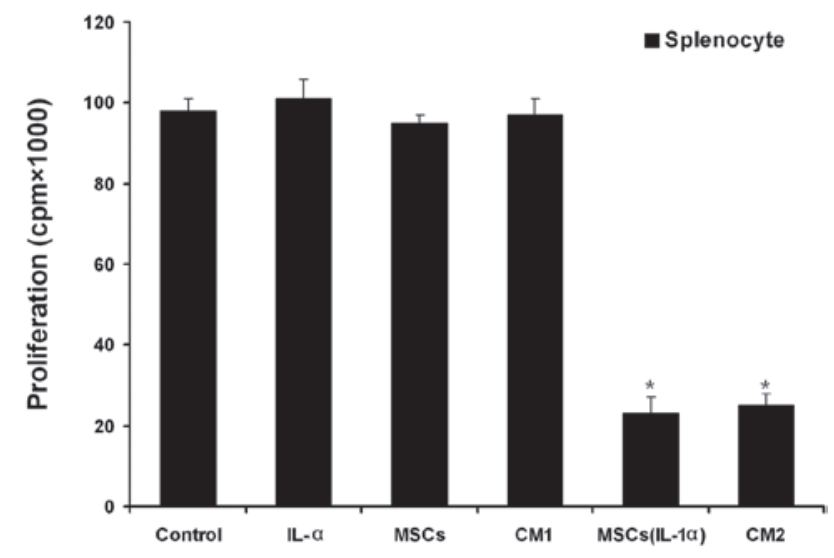

Figure 4. IL-1 $\alpha$ induced the immunosuppressive function of MSCs. Balb/c mouse MSCs were pretreated with IL-1 $\alpha(20 \mathrm{ng} / \mathrm{ml})$ for $12 \mathrm{~h}$. Balb/c splenocytes were activated by incubation with ConA $(5 \mu \mathrm{g} / \mathrm{ml})$ for $72 \mathrm{~h}$ and IL-2 $(20 \mathrm{ng} / \mathrm{ml})$ was added to maintain proliferation. Splenocytes $\left(1 \times 10^{5} /\right.$ well $)$ were co-cultured with MSCs at a ratio of 10:1 in a 96-well plate for $72 \mathrm{~h}$ Conditioned media, collected from the MSCs, were added to the splenocyte culture system and the proliferation of the splenocytes was observed for $72 \mathrm{~h} . \mathrm{A}^{3} \mathrm{H}$-incorporation assay was employed to assess the proliferation of the splenocytes ( $\mathrm{P}<0.05)$. MSCs, mesenchymal stem cells; ConA, concanavalin $\mathrm{A}$; cpm, counts per min.

RM-1 prostate cancer cells are not rejected by C57BL/6 mice when co-injected with MSCs. To determine the immunosuppressive effect of MSCs in the promotion of tumor growth in vivo, we combined RM-1 cells with MSCs, which were either pre-incubated with IL-1 $\alpha$ or not, and implanted subcutaneously in C57/BL6 mice. The RM-1 cells developed into tumors when implanted in Balb/c mice; however, these cells were rejected by the C57/BL6 mice. When RM-1 cells were co-injected with MSCs, the tumor incidence markedly increased. Furthermore, compared with the control group, IL-1 $\alpha$-pretreated MSCs further enhanced the tumor incidence (Fig. 3). In addition, we found that the only conditioned medium able to increase the RM-1 tumor incidence in the C57/BL6 mice was that obtained
A

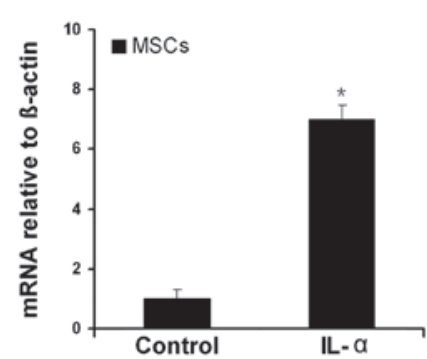

C

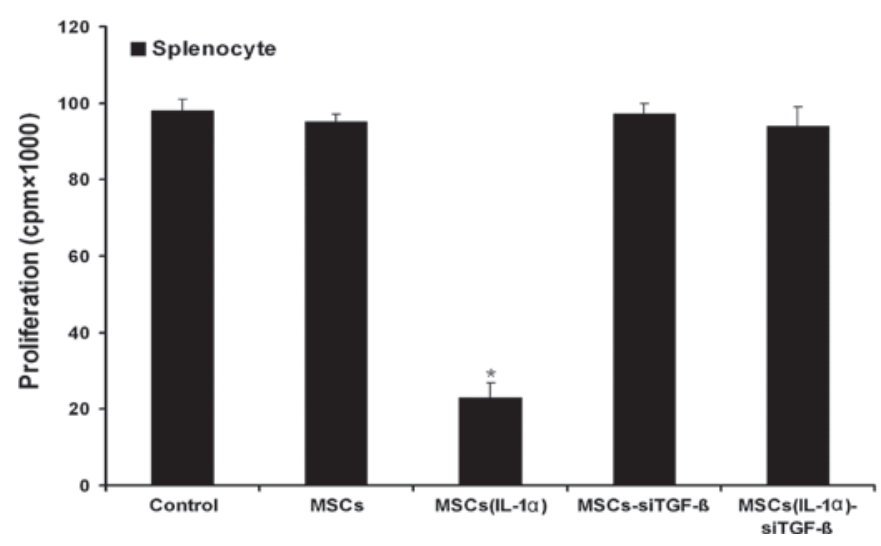

Figure 5. Immunosuppressive function of MSCs was induced by IL-1 $\alpha$ in a TGF- $\beta$-dependent manner. Balb/c mouse MSCs were pretreated with IL-1o (20 ng/ml) for $12 \mathrm{~h}$. (A) Real-time PCR was employed to examine the expression levels of TGF- $\beta$ mRNA in the MSCs. (B) Western blotting was used to detect the expression levels of TGF- $\beta$ protein. (C) Splenocytes were co-cultured with MSCs with or without TGF- $\beta$ siRNA. Cell proliferation was examined by a ${ }^{3} \mathrm{H}$-incorporation assay after $72 \mathrm{~h}\left({ }^{*} \mathrm{P}<0.05\right)$. MSCs, mesenchymal stem cells; cpm, counts per min.

from IL-1 $\alpha$-pretreated MSCs (Fig. 3). Taken together, the results suggest that IL- $1 \alpha$ induces the immunosuppressive action of the MSCs, which may help the RM-1 cells to escape from immune rejection by the C57/BL6 mice.

IL-1 $\alpha$ induces the immunosuppressive function of MSCs by upregulating TGF- $\beta$. We employed the MLR to examine the immunosuppressive function of MSCs induced by IL-1 $\alpha$. We activated the splenocytes from Balb/c mice with Con A for $72 \mathrm{~h}$ and then expanded them with IL-2. The activated splenocytes were co-cultured with MSCs that were either pretreated with IL-1 $\alpha$ or not. The results demonstrated that the MSCs did not inhibit the proliferation of splenocytes unless they were pretreated with IL-1 $\alpha$ (Fig. 4). In addition, conditioned media collected from the MSCs were added to the activated splenocyte culture system and the proliferation of the splenocytes was examined. The conditioned medium obtained from IL- $1 \alpha$-pretreated MSCs effectively inhibited the proliferation of the splenocytes (Fig. 4).

To detect the mechanism by which IL-1 $\alpha$ induced the immunosuppressive function of the MSCs, we examined the production of immunosuppression-related cytokines in the MSCs following exposure to IL-1 $\alpha$. Real-time PCR and western blotting were employed to detect the expression of immunosuppression-related cytokines in the MSCs. As shown 
A

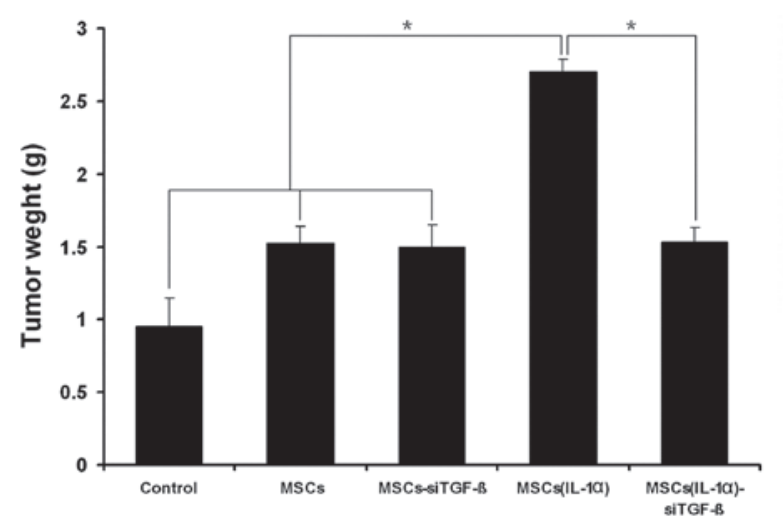

B

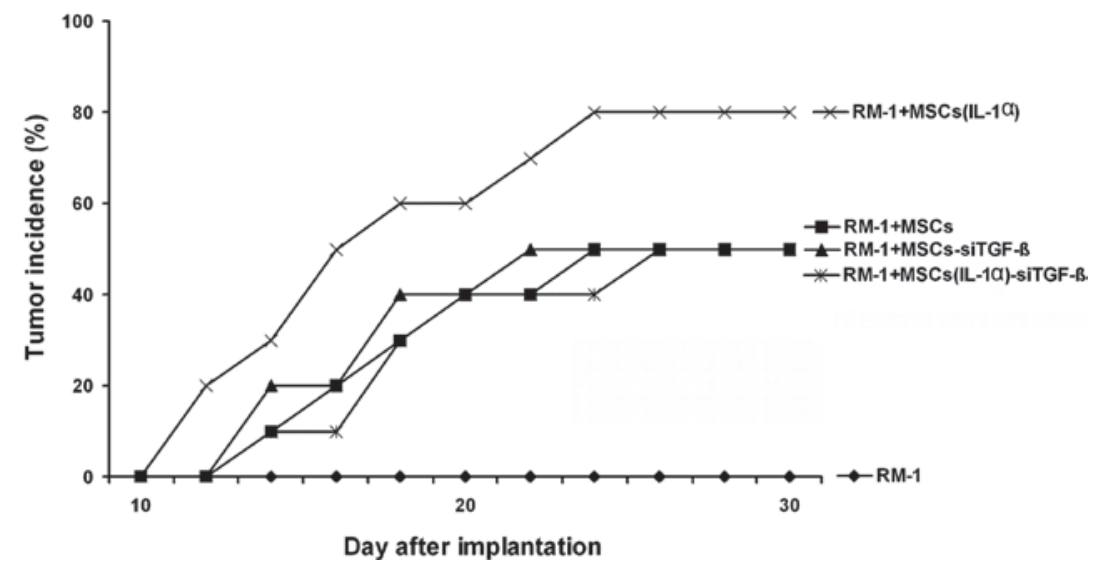

Figure 6. Enhancement of RM-1 cell growth in vivo by MSCs was prevented by TGF- $\beta$ siRNA. (A) TGF- $\beta$ siRNA was transfected into Balb/c mouse MSCs using Lipofectamine. The MSCs ${ }^{\text {si-TGF- } \beta}$ were stimulated by IL- $1 \alpha(20 \mathrm{ng} / \mathrm{ml})$ for $12 \mathrm{~h}$ and co-injected with RM-1 cells $\left(5 \times 10^{6}\right)$ in the armpit area of Balb/c mice. The animals were sacrificed 14 days following implantation and the tumors were dissected. RM-1 tumor weights were determined $(\mathrm{P}<0.05)$. (B) Transfection of TGF- $\beta$ siRNA into C57/BL6 mouse MSCs was performed using a Lipofectamine. The MSCs ${ }^{\text {si-TGF- } \beta}$ were stimulated by IL-1 $\alpha$ ( $\left.20 \mathrm{ng} / \mathrm{ml}\right)$ for $12 \mathrm{~h}$ and coinjected with RM-1 cells $\left(5 \times 10^{6}\right)$ in the armpit area of C57/BL6 mice. Tumor incidence was observed. MSCs, mesenchymal stem cells.

in Fig. 5A and B, IL-1 $\alpha$ effectively upregulated the expression of TGF- $\beta$ in the MSCs. To confirm the role of TGF- $\beta$ in the immunosuppressive function of the MSCs, TGF- $\beta$ siRNA was used to inhibit the expression of TGF- $\beta$ in the MSCs. In mixed co-cultures of splenocytes and MSCs pre-stimulated by IL-1 $\alpha$, splenocyte proliferation was restored to normal levels by TGF- $\beta$ siRNA (Fig. 5 C). These results suggest that TGF- $\beta$ is the key factor that mediates the IL-1 $\alpha$-induced immunosuppressive effect of the MSCs on splenocyte proliferation.

Enhancement of RM-1 cell growth in vivo by MSCs was prevented by TGF- $\beta$ siRNA. We have demonstrated that IL-1 $\alpha$ effectively induces the ability of MSCs to promote the growth of RM-1 cells in vivo and that this enhancement may be associated with the immunosuppressive function of MSCs. We have also shown that the IL-1 $\alpha$-induced immunosuppressive action of the MSCs was mediated by TGF- $\beta$. Therefore, we used TGF- $\beta$ siRNA to confirm the role of TGF- $\beta$ in the immunosuppressive effect of the MSCs. The results showed that the promotive effect of MSCs on tumor growth in vivo induced by IL- $1 \alpha$ was inhibited by TGF- $\beta$ siRNA (Fig. 6A). Furthermore, the enhancement of RM-1 tumor incidence in the C57/BL6 mice by IL-1 $\alpha$-pretreated MSCs was reduced following the use of TGF- $\beta$ siRNA (Fig. 6B). These data suggest that TGF- $\beta$ is a key factor in the immunosuppressive action of MSCs that enables RM-1 cells to escape from immune injury.

\section{Discussion}

It has been reported that MSCs are able to differentiate into osteoblasts, chondrocytes, adipocytes, myotubes, neural cells and hematopoietic supporting stroma $(3,4,20)$. MSCs have been recognized to contribute to the regeneration of a wide variety of organs and to the healing of certain diseases (21-23). Furthermore, MSCs also are influential in the treatment of various degenerative diseases and immune disorders. Therefore, MSCs have been regarded as a potential therapy for numerous diseases. However, the immunosuppressive effects of MSCs have been reported in several studies (9-12), and in certain circumstances, the immunosuppressive effect may promote tumor growth. Therefore, it is essential to observe the effect of MSCs on tumor growth in an inflammatory environment.

In this study, we investigated the underlying mechanism by which MSCs enable prostate cancer cells to escape from immune surveillance in the inflammatory microenvironment. Firstly, we demonstrated that in comparison to the control groups, MSCs pretreated with IL-1 $\alpha$ effectively promoted the growth of the mouse prostate cancer cell line RM-1 in vivo. Furthermore, when RM-1 prostate cancer cells were co-injected with MSCs pretreated with IL-1 $\alpha$, tumor incidence significantly increased in allogeneic recipients. In addition, we investigated the mechanism by which MSCs enable RM-1 cells 
to escape from immune injury. The results revealed that treatment with IL- $1 \alpha$ led to the upregulation of TGF- $\beta$ in MSCs. The inflammatory cytokine-induced promotive effect of MSCs on RM-1 cells in vivo was inhibited by TGF- $\beta$ siRNA. The results of our study suggest that inflammatory cytokines induce the immunosuppressive function of MSCs, which enables prostate cancer cells to escape from immune injury.

Several studies have demonstrated that MSCs are able to promote tumor growth. Hall et al have shown that the co-culturing of ALL cell lines with VCAM-1-overexpressing stromal cells enhanced the survival of the leukemic cells in a PI-3 kinase-dependent manner, compared with co-culturing with stromal cells expressing only endogenous VCAM-1 (17). Djouad et al revealed that MSCs exhibited side effects related to systemic immunosuppression which induced tumor growth in vivo (18). Conversely, MSCs have been reported to be anti-tumorigenic in a mouse model of Kaposi's sarcoma by inhibiting AKT activity (19). Liu et al have shown that IFN- $\gamma$ and TNF- $\alpha$ are able to induce the upregulation of VEGF in MSCs, which may be a significant mechanism for the promotion of tumor growth (24). The results of our study suggest that inflammatory cytokines, including IL- $1 \alpha$, are key factors that regulate the actions of MSCs on tumor growth.

There are still a number of problems limiting the application of MSCs in clinical therapy, particularly the regulatory effect of the microenvironment. Therefore, it is necessary to investigate the biological activity of the MSCs in combination with the microenvironment, in order to improve the clinical application of MSCs in tissue engineering and regenerative medicine. Our results suggest that inflammatory cytokines, including IL-1 $\alpha$, are key factors that induce the immunosuppressive activity of MSCs and enable the tumor cells to evade immune surveillance. Therefore, the use of MSCs in cancer therapy should be carried out with caution.

\section{Acknowledgements}

This study was supported by the Science Foundation for Young Scientists of Guangxi (grant no. 0991075), the Key Research Project of Guangxi Health Department (grant no. 2011080), the National Natural Science Foundation (grant nos. 2011080 and 30860329) and the Guangxi Natural Science Foundation (grant no. 2010gxnsfa013240).

\section{References}

1. Deans RJ and Moseley AB: Mesenchymal stem cells: biology and potential clinical uses. Exp Hematol 28: 875-884, 2000.

2. Bianco P and Gehron Robey P: Marrow stromal stem cells. J Clin Invest 105: 1663-1668, 2000 .

3. Pittenger MF, Mackay AM, Beck SC, Jaiswal RK, Douglas R, Mosca JD, Moorman MA, Simonetti DW, Craig S and Marshak DR: Multilineage potential of adult human mesenchymal stem cells. Science 284: 143-147, 1999.

4. Barry FP and Murphy JM: Mesenchymal stem cells: clinical applications and biological characterization. Int J Biochem Cell Biol 36: 568-584, 2004

5. Bianco P, Robey PG and Simmons PJ: Mesenchymal stem cells: revisiting history, concepts, and assays. Cell Stem Cell 2: 313-319, 2008.

6. Anjos-Afonso F and Bonnet D: Nonhematopoietic/endothelial SSEA-1+ cells define the most primitive progenitors in the adult murine bone marrow mesenchymal compartment. Blood 109: 1298-1306, 2007.
7. In 't Anker PS, Scherjon SA, Kleijburg-van der Keur C, de GrootSwings GM, Claas FH, Fibbe WE and Kanhai HH: Isolation of mesenchymal stem cells of fetal or maternal origin from human placenta. Stem Cells 22: 1338-1345, 2004.

8. Zuk PA, Zhu M, Mizuno H, Huang J, Futrell JW, Katz AJ, Benhaim P, Lorenz HP and Hedrick MH: Multilineage cells from human adipose tissue: implications for cell-based therapies. Tissue Eng 7: 211-228, 2001.

9. Sato K, Ozaki K, Oh I, Meguro A, Hatanaka K, Nagai T, Muroi K and Ozawa K: Nitric oxide plays a critical role in suppression of T-cell proliferation by mesenchymal stem cells. Blood 109: 228-234, 2007.

10. Rasmusson I, Ringdén O, Sundberg B and Le Blanc K: Mesenchymal stem cells inhibit lymphocyte proliferation by mitogens and alloantigens by different mechanisms. Exp Cell Res 305: 33-41, 2005.

11. Krampera M, Glennie S, Dyson J, Scott D, Laylor R, Simpson E and Dazzi F: Bone marrow mesenchymal stem cells inhibit the response of naive and memory antigen-specific $\mathrm{T}$ cells to their cognate peptide. Blood 101: 3722-3729, 2003

12. Di Nicola M, Carlo-Stella C, Magni M, Milanesi M, Longoni PD, Matteucci P, Grisanti S and Gianni AM: Human bone marrow stromal cells suppress T-lymphocyte proliferation induced by cellular or nonspecific mitogenic stimuli. Blood 99: 3838-3843, 2002.

13. Koç ON, Day J, Nieder M, Gerson SL, Lazarus HM and Krivit W: Allogeneic mesenchymal stem cell infusion for treatment of metachromatic leukodystrophy (MLD) and Hurler syndrome (MPS-IH). Bone Marrow Transplant 30: 215-222, 2002.

14. Djouad F, Fritz V, Apparailly F, Louis-Plence P, Bony C, Sany J, Jorgensen $C$ and Noël D: Reversal of the immunosuppressive properties of mesenchymal stem cells by tumor necrosis factor alpha in collagen-induced arthritis. Arthritis Rheum 52: 1595-1603, 2005.

15. Zappia E, Casazza S, Pedemonte E, Benvenuto F, Bonanni I, Gerdoni E, Giunti D, Ceravolo A, Cazzanti F, Frassoni F, et al: Mesenchymal stem cells ameliorate experimental autoimmune encephalomyelitis inducing T-cell anergy. Blood 106: 1755-1761, 2005.

16. Nakamizo A, Marini F, Amano T, Khan A, Studeny M, Gumin J, Chen J, Hentschel S, Vecil G, Dembinski J, et al: Human bone marrow-derived mesenchymal stem cells in the treatment of gliomas. Cancer Res 65: 3307-3318, 2005.

17. Hall BM, Fortney JE, Taylor L, Wood H, Wang L, Adams S, Davis $S$ and Gibson LF: Stromal cells expressing elevated VCAM-1 enhance survival of B lineage tumor cells. Cancer Lett 207: 229-239, 2004.

18. Djouad F, Plence P, Bony C, Tropel P, Apparailly F, Sany J, Noël D and Jorgensen C: Immunosuppressive effect of mesenchymal stem cells favors tumor growth in allogeneic animals. Blood 102: 3837-3844, 2003.

19. Khakoo AY, Pati S, Anderson SA, Reid W, Elshal MF, Rovira II, Nguyen AT, Malide D, Combs CA, Hall G, et al: Human mesenchymal stem cells exert potent antitumorigenic effects in a model of Kaposi's sarcoma. J Exp Med 203: 1235-1247, 2006.

20. Xu W, Zhang X, Qian H, Zhu W, Sun X, Hu J, Zhou H and Chen Y: Mesenchymal stem cells from adult human bone marrow differentiate into a cardiomyocyte phenotype in vitro. Exp Biol Med (Maywood) 229: 623-631, 2004.

21. D'Agostino B, Sullo N, Siniscalco D, De Angelis A and Rossi F: Mesenchymal stem cell therapy for the treatment of chronic obstructive pulmonary disease. Expert Opin Biol Ther 10: 681-687, 2010.

22. Mazzini L, Ferrero I, Luparello V, Rustichelli D, Gunetti M, Mareschi K, Testa L, Stecco A, Tarletti R, Miglioretti M, et al: Mesenchymal stem cell transplantation in amyotrophic lateral sclerosis: a phase I clinical trial. Exp Neurol 223: 229-237, 2010.

23. Loebinger MR, Eddaoudi A, Davies D and Janes SM: Mesenchymal stem cell delivery of TRAIL can eliminate metastatic cancer. Cancer Res 69: 4134-4142, 2009.

24. Liu Y, Han ZP, Zhang SS, Jing YY, Bu XX, Wang CY, Sun K, Jiang GC, Zhao X, Li R, et al: Effects of inflammatory factors on mesenchymal stem cells and their role in the promotion of tumor angiogenesis in colon cancer. J Biol Chem 286: 25007-25015, 2011. 